\title{
Ways to Develop Vehicle Operating Companies and Transport System in the Republic of Uzbekistan
}

\author{
Kalonov Mukhiddin Baxritdinovich \\ Institute for Advanced training and retraining of auto transport personnel, 5A Mumtoz Street, Yashnobod district, \\ Tashkent 100147, Uzbekistan
}

\begin{abstract}
.
This article is devoted to the issues on the role of motor vehicles in the transport system in Uzbekistan as well as prospects of this system development in future. In addition, the article studies the advantages and disadvantages of motor vehicles as well as provides peculiarities related to the transport system development in our republic. Moreover, based on the research results the author has developed proposals and recommendations aimed at the efficient performance of the motor vehicles.
\end{abstract}

Keywords: vehicle operating companies, motor vehicles, revenues, expenses, accounting. DOI: $10.7176 / \mathrm{EJBM} / 11-3-21$

\section{Introduction.}

It is well-known fact, that the development of economic relations between countries, expansion of humanitarian aid among countries, urbanization, production of material resources and consumption growth, as well as reduction of transportation costs in mutual relations cause a need for accounting transportation costs. European vehicle operating companies mainly account for the costs of production (service) classified by three groups: fixed costs, variable costs and indirect costs. However, in the United States, transport costs are accounted by dividing them into 8 groups. Within this framework, the problems of the development of transportation services, the management of the cost of car transportation under conditions of the international globalization, and the need to keep track of incomes and expenses are considered to be the topical issues challenged by the economy.

The efforts to enhance the well-being of the population, improve the passenger and freight transportation system, establish traffic, safety and quality requirements based on the advanced foreign experience have resulted in the creation of vehicle operating companies that meet the world standards. Currently, vehicle operating companies are gradually carrying out a number of activities aimed at the provision of quality transportation services to the population and legal entities. In addition, the Strategy for further development of the Republic of Uzbekistan has determined the tasks such as "Pursuing an active investment policy aimed at modernization, technical and technological renewal of production, implementation of manufacturing, transport, communications and social infrastructure projects" (Strategy 2017). These tasks demonstrate the necessity to improve accounting of the revenues and expenses of vehicle operating companies.

It should be noted that currently researches aimed at the cost analysis in the automotive industry of the countries of the world, summarizing the data of the initial cost accounting, studying the information and analytical database for cost management and accounting, improving the theoretical and practical basis for the development of high cost effective projects, as well as rendering services which enable to earn high revenues simultaneously with the expenses reduction are being carried out.

\section{The aim of the research.}

The main aim of this article is to assess the role the of motor vehicles in the transport system in Uzbekistan, the prospects of developing this system in future, determine the factors affecting the development of the vehicle operating companies. In addition, the aim implies development of the proposals and recommendations aimed at the efficient performance of the motor vehicles.

\section{Literature review.}

Many foreign scientists such as T.U. Schultz, M. Dorigo, E.A.Balas, K.Sh.Tomas, G.S.Becker, L.F.Lebedeva, A.A. Bachurin, V.A. Korchagin, A.V.Gubenko, B.A.Dubovikov, B.I.Bashkatov, G.S.Dugin, O.N.Dunayev, A.K.Glukhov, I.I.Yeliseyeva, L.V.Kantorovich, S.V.Jukov, A.A. Chebotaev devoted their researches to the issues of improving accounting of revenues and expenses. In addition, these issues have been considered in the scientific papers of B.A. Khasanov, K.B.Urazov, R.O.Xolbekov, S.Kadirhonov, U.T.Fayzieva who have studied existing methodologies and ways of improving the accounting of revenues and expenses in their practical aspects.

Gradual implementation of reforms in the country leads to the sustainable development of the economy of the country and consequently, the main goal is to improve the living standards of the population. With the development of industrial, agricultural, export-import relations and other macroeconomic indicators in our Republic, there has been launched the development of the services sector which is considered to be the main link 
in these areas. Meanwhile, the types of services vary with the account of the society's demands and are expanding on the basis of the program of development of the services sector. This can be justified by the statistical data provided below (Figure 1).

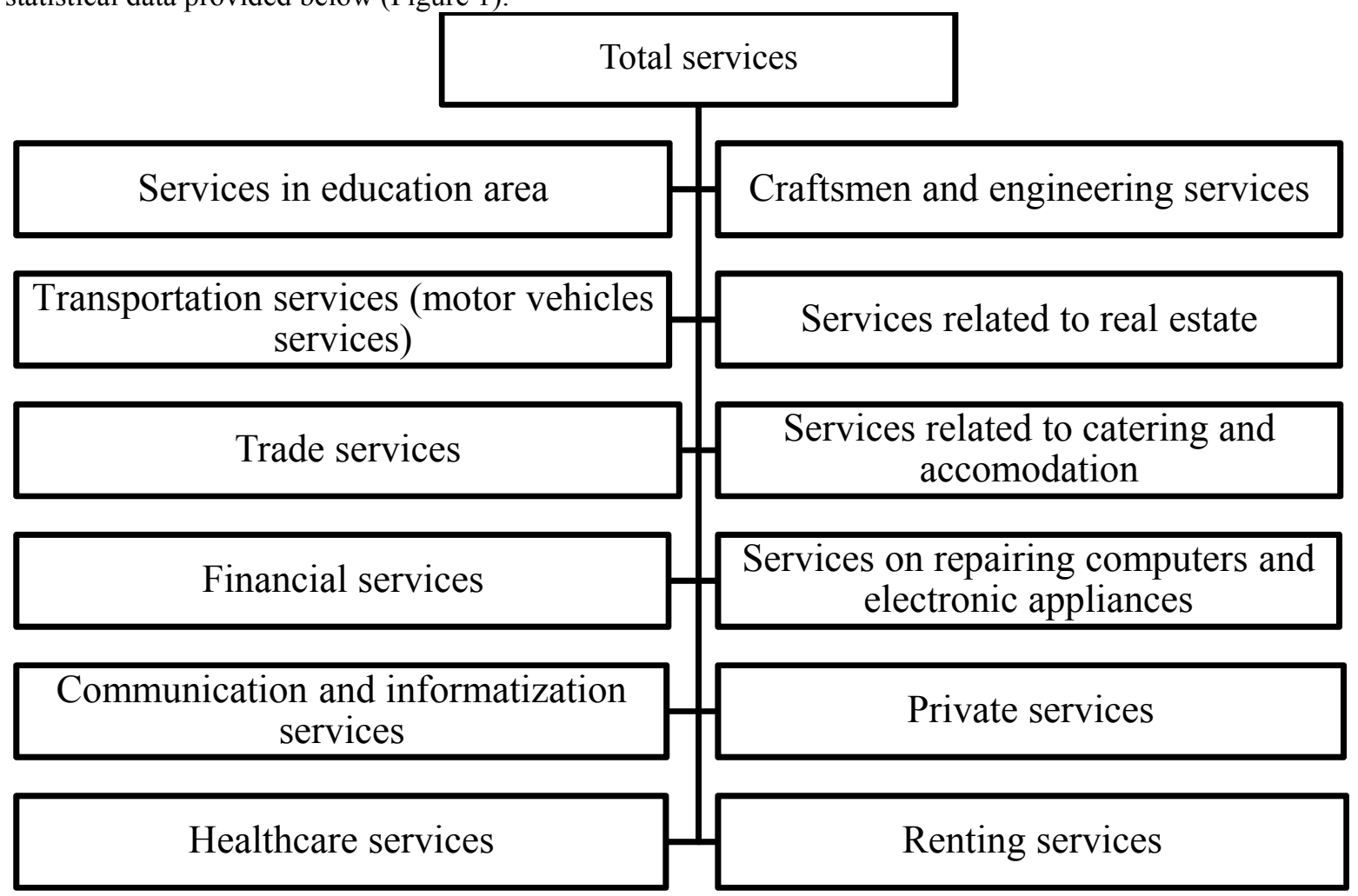

Figure 1. Services structure in our Republic ${ }^{1}$

Thus, transportation services sector is considered to be one of the areas and it interconnects all industries and services. In this regard, lagging behind the development of the sector or the high prime-cost of services in this area will definitely have an impact on any other activity.

Transport services have become one of the most important areas of transportation and logistics systems in recent years within the framework of current trends in the world economy, as well as prospective economic and social development of the world countries. The increase in the number of people around the globe has necessitated the development of global transport network.

The impact of natural, geographical, economic, political, social and many other factors is evident in the unprecedented growth of the global transport. Alongside with the increase in the length of interstate communication routes, the traditional types of transport networks have been significantly reconstructed. In addition, transportation capacities have been considerably significantly expanded, and, as a result, the transportation speed has increased and the quality of transportation services has improved. At the same time, new types of modern vehicles are being created, and they are rapidly gaining its place throughout the world.

The transport system of each country serves to meet the needs of the society. The governments always pay a particular attention to the satisfaction of the needs of this service's users. Therefore, the transport system has always been an integral part of the economy.

According to the research conducted by Bulko O.S., railway transport was dominant in the XIX century when transport services were used, while in the XX century motor vehicle transport was dominating (Bulko, 2016). Currently, motor vehicles are considered to be the world leader in the world with $80 \%$ share in the passenger carriage.

\section{Methodology.}

Such research methods as observation, data collection, grouping, comparison, statistical analysis of data, and interviews have been widely used in the research.

\section{Discussion and analysis.}

The biggest share in cargo transportation belongs to the river transportation. According to the results of the

\footnotetext{
${ }^{1}$ Developed by the author on the basis of the data of the State Statistics Committee of the Republic of Uzbekistan.
} 
survey, this part of the transportation constitutes $62 \%$ (Bulko, 2016). However, not all countries have access to this type of transport. Due to the opportunity of river transport types to carry both small and big-size cargo in big volumes, as well as its availability because of cheap prices, it enables to transport even several automobiles at the same time that, in turn, leads to the opportunity to deliver cargoes of the big size.

In our opinion, it is recommended to evaluate advantages of each type of the service and the role of this transport type proceeding from the capabilities of each country's own internal capacity and peculiarities of transportation services rendered.

Public transport network also implements significant economic, political, social, cultural, agrarian, medical, defense and other functions at the national level. This network is a large and sophisticated set of businesses that include independent networks, various types of the linehaul vehicles, urban and industrial transport.

Despite its administrative and economic independence, all types of transport work in a certain interconnected manner and affect both the transportation process and final technical and economic results. It manifests itself as a necessary prerequisite for the rational layout of production and high productivity of social activities.

The major part of vehicles and their components were imported into the Republic of Uzbekistan until 1991. This, in turn, negatively affected the production process. Nowadays our republic has developed an independent automotive industry. Over 130 regulations and statutory acts have been developed in our country aimed at improving the transport industry, providing traffic safety, enhancing the culture of passenger carriage services.

The first stage of the automotive industry development in the Republic of Uzbekistan was establishing the manufacturing process of motor vehicles. Currently due to the attraction of foreign investments the government tries to manufacture details and spare parts of the motor vehicles; further improvement of the production of buses and trucks and enhancing their competitiveness; renewal of the motor vehicles' parks which, in turn, will lead to the increase of the transportation security; further reduction of wastes to the environment; occupying a worthy niche in the international market; expanding the range of services through the production of commercial motor cars; as well as implement comprehensive reforms aimed at further improvement of the situation in vehicle operating companies.

Above we have considered the issues related to rendering transportation services and their role. Below we will analyze the tendency of development of transport services in the republic. In this regard we can see that the biggest share in the overall volume of cargo transportation belongs to motor vehicles. For the last several years the main share of the cargo transportation in our country belongs precisely to motor vehicles.

With regard to statistical indicators, road transportation services, including cargo transportation, have been growing gradually since the early years of the independence.

In 1990282,9 million tons of cargo were transported by road, while the volume of cargo transported in 2017 was over 1 billion 13 million tons (Table 1).

Table 1. Basic indicators of the transport performance in the Republic of Uzbekistan in 2014-2017

(Collection of statistic materials, 2018)

\begin{tabular}{|l|c|c|c|c|c|}
\hline \multicolumn{1}{|c|}{ Indicators } & $\mathbf{2 0 1 4}$ & $\mathbf{2 0 1 5}$ & $\mathbf{2 0 1 6}$ & $\mathbf{2 0 1 7}$ & $\begin{array}{c}\text { \% in 2014 in relation to } \\
\mathbf{2 0 1 7}\end{array}$ \\
\hline I.1. Cargo transportation, total (mIn.tons) & 1458,9 & 1527,0 & 1132,5 & 1146,2 & 78,5 \\
\hline including: & & & & & \\
\hline Railways & 65,7 & 67,2 & 67,6 & 67,9 & 103,3 \\
\hline Airways & 23,0 & 24,6 & 26,5 & 26,4 & 114,8 \\
\hline Gas facilities & 65,8 & 60,0 & 65,2 & 65,1 & 99,0 \\
\hline Motor vehicle & 1327,4 & 1399,8 & 1002,8 & 1013,1 & 76,3 \\
\hline $\begin{array}{l}\text { 2. Cargo turnover - total (billion } \\
\text { tons/km) }\end{array}$ & 85,7 & 86,9 & 65,3 & 66,9 & 78,0 \\
\hline including: & & & & & \\
\hline Railways & 22,9 & 22,9 & 22,9 & 22,9 & 100,0 \\
\hline Airways & 0,125 & 0,131 & 0,132 & 0,156 & 124,8 \\
\hline Gas facilities & 31,2 & 30,0 & 28,9 & 30,2 & 96,8 \\
\hline Motor vehicle & 31,5 & 33,9 & 13,3 & 13,6 & 43,1 \\
\hline $\begin{array}{l}\text { II.1. Passengers transported, total, } \\
\text { mIn.people }\end{array}$ & 7335,3 & 7598,2 & 5560,4 & 5679,0 & 77,4 \\
\hline including: & & & & & \\
\hline Railways & 19,1 & 20,1 & 20,5 & 21,1 & 110,5 \\
\hline Airways & 2,3 & 2,2 & 2,1 & 2,2 & 95,6 \\
\hline Motor vehicle & 7244,4 & 7511,4 & 5480,8 & 5591,3 & 77,2 \\
\hline Electric transport (subway) & 54,0 & 52,3 & 53,5 & 61,6 & 114,0 \\
\hline
\end{tabular}




\begin{tabular}{|l|c|c|c|c|c|}
\hline \multicolumn{1}{|c|}{ Indicators } & $\mathbf{2 0 1 4}$ & $\mathbf{2 0 1 5}$ & $\mathbf{2 0 1 6}$ & $\mathbf{2 0 1 7}$ & $\begin{array}{c}\text { \% in 2014 in relation to } \\
\mathbf{2 0 1 7}\end{array}$ \\
\hline $\begin{array}{l}\text { 2. Passengers turnover, total, billion } \\
\text { people/km }\end{array}$ & 100,1 & 106,0 & 126,0 & 130 & 129,9 \\
\hline including: & & & & & \\
\hline Railways & 3,7 & 3,8 & 4,0 & 4,3 & 116,2 \\
\hline Airways & 7,0 & 6,8 & 6,7 & 7,5 & 107,1 \\
\hline Motor vehicle & 88,9 & 95,0 & 114,9 & 117,7 & 132,4 \\
\hline Electric transport (subway) & 0,4 & 0,4 & 0,4 & 0,5 & 125 \\
\hline
\end{tabular}

According to the data presented in Table 1, in 2017 cargo transportation decreased in comparison with 2014 and the main growth was observed in 2015. However, the volume of cargo transportation through railways and airports has increased. Even though the transportation by air has increased significantly by $14,8 \%$, it is still a very small indicator in terms of cargo transportation. Transportation by motor vehicles is illustrated by the biggest indicator.

Motor vehicle transport plays a major role in the process of passenger carriage. In this direction the highest growth is represented by the railways transport and accounts for $10,5 \%$, but this indicator is still very low in terms of the number of passengers transported.

Thus it is possible to make a conclusion that the transportation by motor vehicles has the highest share in terms of the volumes of cargo.

As we have mentioned above, the lack of large rivers flowing across our republic, inadequate condition of local railway lines, and the high cost of air transportation in some extent have created preconditions for motor vehicles to become a leading type of transport in cargo transportation.

Passenger carriage by motor transport in 2014 amounted to 88,9 billion passengers, and in 2017 it was 117,7 billion passengers which is 1,3 times more than in 2014 .

In the Republic of Uzbekistan the volume of transportation of the main cargo and passenger is influenced by certain factors affecting the road transport and its development.

O.G. Tomorevskaya and others have determined the factors that may influence the development of motor vehicles (Tomorevskaya, 1990), (Figure 2):

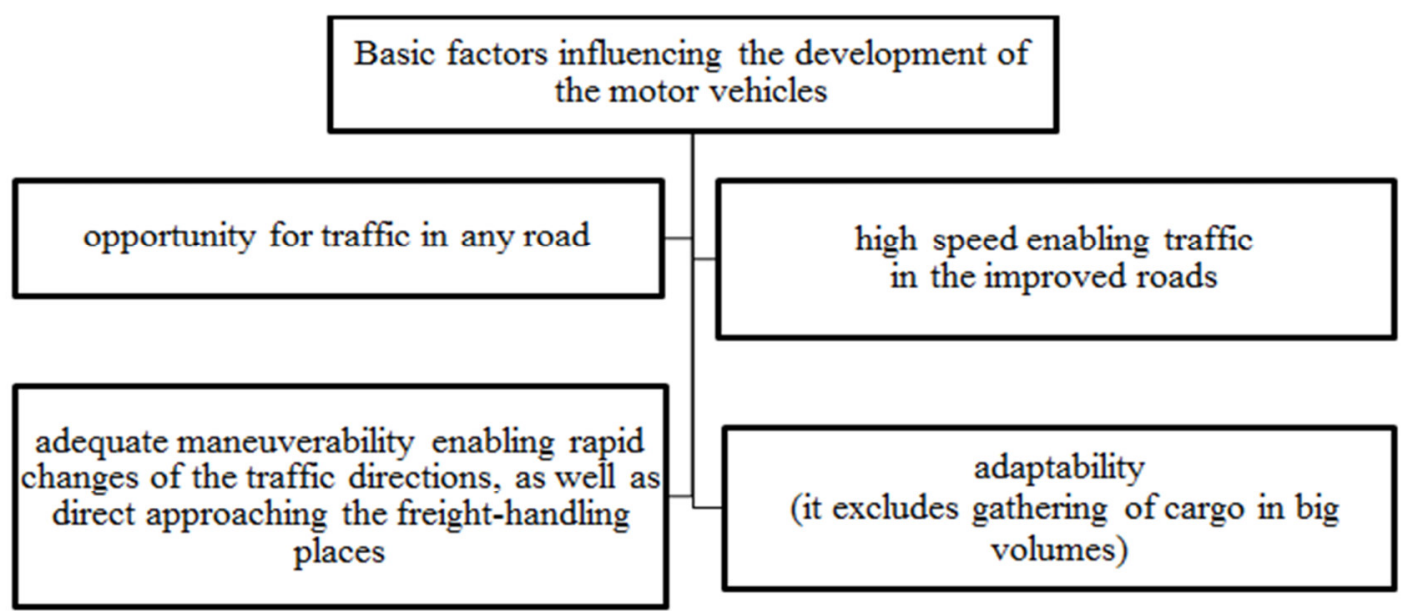

Figure 2. Basic factors influencing the development of the motor vehicles

The leading role of the transportation services, convenience of using this transport, as well as the low cost of using this type of transport can cause the development of this type of transport.

One of the peculiarities of vehicle operating companies is that they can operate at almost any level of technical support and sometimes even without such a base. Vehicle operating companies may also have a certain number of motor vehicles, drivers and management staff. In this case, maintenance and repair of the vehicle can be done by simple facilities, and more complicated repairs are performed on the basis of the technical support of the other company. In addition it should be noted that such a vehicle operating company can achieve high profitability (at least in its initial stages), with less costs and even without its technical support base.

Thus within this framework, motor vehicles are different from other types of transport with respect to not only construction of roads for the existing vehicles, but also in terms of the organization of ports and ships, and the availability of aerodromes and communication equipment.

Currently the development of all types of transport in the Republic of Uzbekistan is crucially important. However, as this research illustrates, motor vehicles occupy a significant position in passenger and cargo transportation. Obviously, motor vehicles are dominating in rendering passenger transportation services 
throughout the world, but river transport services are still widely used in cargo transportation. It should be noted that in our country motor vehicles play a particular role in rendering cargo transportation services.

Furthermore, factors specified by foreign researchers and scientists as the basic factors for the development of motor vehicles have general character and not suitable for all countries.

\section{Conclusion.}

In our opinion, the main reasons why the biggest volume of cargo transportation relates to the motor vehicles are the following:

- convenience of the cargo transportation by motor vehicles;

- favourable opportunities of carriage of small-size and small-volume cargo;

- high costs of airway transportation services;

- insufficient development of railways;

- absence of opportunities to use river transportation services;

- availability to purchase motor vehicles.

Proceeding from the statements above, that not only the development of the transport system, but also the geographical location are significant factors for the development of motor vehicles system.

As the research illustrates, the motor vehicles have both advantages and disadvantages (Table 2).

Table 2. Advantages and disadvantages of motor vehicles ${ }^{1}$

\begin{tabular}{|l|l|}
\hline Advantages & Disadvantages \\
\hline $\begin{array}{l}\text { Delivery of products from the manufacturer to the } \\
\text { consumer }\end{array}$ & $\begin{array}{l}\text { Spending much time in general in the process of the } \\
\text { products' delivery }\end{array}$ \\
\hline $\begin{array}{l}\text { Fast delivery of products which results in prevention } \\
\text { of their gathering in one place }\end{array}$ & Huge demand of the labour force \\
\hline Avoidance of loss and damage to products & $\begin{array}{l}\text { Absence of availability to deliver the products of the } \\
\text { big size and big volume }\end{array}$ \\
\hline Fast and reliable delivery of products & Much fuel consumption (in general terms) \\
\hline
\end{tabular}

According to the results of the research it is possible to make a conclusion that the contribution of motor vehicles to the economic development of the country is substantial and serves as the main link between manufacturers of products and their consumers. Therefore, it is necessary to continuously improve the accounting of revenues and expenditures of vehicle operating companies and to establish their efficient performance on the basis of analysis.

In our opinion, in this regard the following measures shall be implemented:

developing criteria for the formation of the revenue and expenditure components in vehicle operating companies;

determining an accounting policy based on the peculiarities of accounting for revenues and expenditures at vehicle operating companies;

performing continuous analysis of factors affecting formation of the accounting policy in vehicle operating companies, as well as reflecting tax relationships in the accounting policy;

paying a particular attention to the calculation of the income gained from the basic activities of vehicle operating companies;

achieving efficiency based on the analysis of factors affecting the revenues of vehicle operating companies; improving the methodology for calculating the profitability and cost-effectiveness of vehicle operating companies;

impact of logistics on expenditures and revenues at vehicle operating companies, as well as analysis of factors affecting logistics expenses and revenues;

improvement of costs analysis of prime-costs at vehicle operating companies.

Implementation of the proposals and recommendations presented in this article, along with the efficient functioning of the motor vehicle transport in our country, will ensure the sustainable development of the motor vehicle companies and provision of high-quality services.

\section{Reference}

1. Decree (2017) Decree of the President of the Republic of Uzbekistan "On Action Strategy for further development of the Republic of Uzbekistan on five priority directions for 2017-2021" Strategy

2. Collection of Statistical materials (2018) Transport and Communication in Uzbekistan.

3. Bulko O.S. et al (2016). Services sector in Belorussia: Problems and development prospects. Minsk.

4. Tomarevskaya O.G., Simkova N.V., Maleyeva A.V. (1990) Analysis of the production and financial activities of the motor vehicles. - M.: Transport.

\footnotetext{
${ }^{1}$ Developed by the author on the basis of the research
} 